TP Periodica Polytechnica Chemical Engineering

\author{
62(3), pp. 359-367, 2018 \\ https://doi.org/10.3311/PPch.11448 \\ Creative Commons Attribution (i)
}

RESEARCH ARTICLE

\section{Comparison of Box-Behnken, Face Central Composite and Full Factorial Designs in Optimization of Hempseed Oil Extraction by $n$-Hexane: a Case Study}

\author{
Olivera S. Stamenković ${ }^{1}$, Milan D. Kostić1 ${ }^{1}$ Dragana B. \\ Radosavljević , Vlada B. Veljković ${ }^{*}$
}

Received 04 September 2017; accepted after revision 12 December 2017

\begin{abstract}
Statistical multivariate methods like Box-Behnken, face central composite and full factorial designs (BBD, FCCD and $F F D$, respectively) in combination with the response surface methodology (RSM) were compared when applied in modeling and optimization of the hempseed oil (HSO) extraction by $n$-hexane. The effects of solvent-to-seed ratio, operation temperature and extraction time on HSO yield were investigated at the solvent-to-seed ratio of 3:1, 6.5:1 or 10:1 $\mathrm{mL} / \mathrm{g}$, the extraction temperature of 20,45 or $70{ }^{\circ} \mathrm{C}$ and the extraction time of 5, 10 or $15 \mathrm{~min}$. All three methods were efficient in the statistical modeling and optimization of the influential process variables and led to almost the same optimal process conditions and predicted HSO yield. Having better statistical performances and being economically advantageous over the FFD with repetition, the BBD or FCCD combined with the RSM is recommended for the optimization of liquid-solid extraction processes.
\end{abstract}

\section{Keywords}

Box-Behnken design, Canabis sativum L., extraction, optimization, response surface methodology

\footnotetext{
${ }^{1}$ Faculty of Technology, University of Niš,

Bulevar oslobođenja 124, 16000 Leskovac, Serbia

${ }^{2}$ Faculty of Technical Sciences, University of Priština,

Kneza Milosa 7, 38220 Kosovska Mitrovica, Serbia

${ }^{*}$ Corresponding author, e-mail: veljkovicvb@yahoo.com
}

\section{Introduction}

The extraction process variables are commonly optimized in order to maximize the yield of desired extractive substance(s) from plant materials. Since a number of process variables can affect the extraction of extractive substances from plant materials, the application of statistical techniques is preferable than the traditional "one-factor-at-a-time" optimization method. By statistical optimization techniques, the influence of the extraction process variables on the yield of desired extractive substance(s) is analyzed through a smaller number of experiments, which reduces greatly laboratory work and reagent consumption. For the optimization of liquid-solid extraction processes, the response surface methodology (RSM) is usually applied in combination with the full factorial design (FFD) [1-3], central composite design (CCD) [4-11] or Box-Behnken design (BBD) [12-14] serving for the data collection. The Plackett-Burman design followed by either CCD [15] or BoxBehnken design [16-18] has also been applied in optimizing liquid-solid extraction processes. The extract yield is usually correlated with the extraction process factors by using the second-order polynomial (quadratic) equation while the statistical significance of the process factors and their interactions are assessed by the analysis of variance (ANOVA). Knowing the functional dependence of the extract yield on the extraction process factors, the optimal levels of the factors can be selected.

Industrial hemp (Cannabis sativa L.) is cultivated for fiber and seed due to high yields of biomass and seed oil. It has multiple industrial applications like in textile, paper, construction, food, feed, pharmaceutical, cosmetic and other industries $[20,21]$. Since recently, hemp has been used for the production of bioethanol and biogas from biomass [20] and biodiesel from seed oil [22, 23]. High seed oil content, fast plant growth and low agricultural inputs make hemp a cost-effective crop for biodiesel production. Cold pressing [24-26], supercritical carbon dioxide extraction [26-29] and solvent extraction [3] have been applied so far for extracting the oil from hemp seeds. Kostic et al. [3] have studied the impact of the process factors on the hempseed oil (HSO) yield reached by solvent extraction using the RSM coupled with a FFD with replication. Besides that, the 
oil recovery from hempseed and its press cake by supercritical carbon dioxide extraction was optimized using the RSM combined with an faced CCD (FCCD) with a central point [28] or a BBD [30], respectively.

The present study deals with comparing the performances of three-factor-three-level BBD and FCCD with the corresponding FFD with replication, which are used in combination with the RSM for the optimization of the HSO extraction by $n$-hexane with respect to solvent-to-seed ratio, operation temperature and extraction time. The main goal was to evaluate if simpler $\mathrm{BBD}$ or FCCD could adequately replace the more expensive, more time-consuming and more tedious FFD with replication in the modeling of oil extraction from seeds. According to the authors' best knowledge, the three designs have not yet been compared to each other with respect to their performances in the optimization of seed oil extraction processes although they differ in the number of experiments and quality of information acquired by their accomplishment.

\section{Experimental}

\subsection{Materials, equipment, extraction conditions and procedure}

Materials, equipment, as well as extraction procedure and conditions were described in details elsewhere [3]. The seed of hemp (Cannabis sativa L.), purchased from a local market, contained $34.93 \mathrm{~g}$ of oil per $100 \mathrm{~g}$ of dried seed and $2.5 \%$ of water. Before extraction, the seed was ground in an electric mill in order to get seed powder having the average particle size of $0.47 \mathrm{~mm}$. The seed powder ( $5 \mathrm{~g}$ ) and $n$-hexane, HPLC grade (Lab-Scan, Dublin, Ireland), in the desired ratio (solvent-to-seed ratio of $3: 1,6.5: 1$ or $10: 1 \mathrm{~mL} / \mathrm{g}$ ) were added to an Erlenmeyer flask (100 mL), connected to a condenser, which was placed in a water bath at 20,45 or $70{ }^{\circ} \mathrm{C}$ for a certain period of time $(5,10$ or $15 \mathrm{~min})$. At the end of the extraction, the liquid extract was separated from the exhausted plant material by vacuum filtration. The cake obtained was washed twice with fresh solvent $(20 \mathrm{~mL})$. The filtrates were combined and evaporated to a constant mass at $50{ }^{\circ} \mathrm{C}$ under vacuum. Experiments were randomly run in order to avoid questionable variability that influences the HSO yield because of extraneous factors.

\subsection{Modeling of experimental results}

The extraction temperature $\left(X_{1}\right)$, solvent-to-seed ratio $\left(X_{2}\right)$ and extraction time $\left(X_{3}\right)$ were optimized to ensure the maximum HSO yield in the batch extraction using $n$-hexane. Each factor consisted of three levels including extraction temperature $\left(20,45\right.$ and $\left.70{ }^{\circ} \mathrm{C}\right)$, solvent-to-seed ratio $(3: 1,6.5: 1$ and $10: 1 \mathrm{~mL} / \mathrm{g})$ and extraction time (5, 10 and $15 \mathrm{~min})$. Two experimental designs, BBD and FCCD, were used in the optimization study. The experimental points of BBD and FCCD are localized at different places of the experimental cubic space, i.e. the
BBD does not contain the vertices of the experimental cubic space, and the FCCD examines borderline regions. However, all experimental points of these two designs are included in the corresponding FFD. The design matrices of the BBD (14 runs) and FCCD (16 runs) are shown in Tables 1 and 2, respectively. These designs were the parts of the corresponding three-factorthree-level FFD with replication (54 runs) [3].

First, the adequacy of the BBD- and FCCD-based models was tested by the sequential sum of squares, lack of fit and model summary statistic tests. These tests select the highest order non-aliased polynomial model where the additional terms are significant, the model with insignificant lack-of-fit and the model maximizing the adjusted and predicted coefficients of determination, $R_{a d j}^{2}$ and $R_{\text {pred }}^{2}$, respectively. Then, the statistical significance of individual process factors and their interactions on HSO yield were assessed by the ANOVA with a confidence level of $95 \%$ (i.e. $p<0.05$ ). A multiple nonlinear regression was used to develop the relationship of HSO yield with the three process factors in the form of the second-order (quadratic) equation:

$$
\begin{aligned}
Y= & b_{0}+b_{1} X_{1}+b_{2} X_{2}+b_{3} X_{3}+b_{12} X_{1} X_{2}+b_{13} X_{1} X_{3} \\
& +b_{23} X_{2} X_{3}+b_{11} X_{1}^{2}+b_{22} X_{2}^{2}+b_{33} X_{3}^{2}
\end{aligned}
$$

where $Y$ is the HSO yield, $b_{0}$ is the constant regression coefficient, $b_{\mathrm{i}}, b_{\mathrm{ii}}$ and $b_{\mathrm{ij}}$ are the linear quadratic and two-factor interaction regression coefficients, respectively $(i, j=1,2,3)$ while $X_{1}, X_{2}$ and $X_{3}$ are temperature, solvent-to-seed ratio and extraction time, respectively. If necessary, the quadratic equation was simplified by eliminating insignificant terms into the linear equation:

$$
Y=b_{0}+b_{1} X_{1}+b_{2} X_{2}+b_{3} X_{3}
$$

The performances of the developed model were statistically assessed by several statistical criteria, such as $F$-value, $p$-value, coefficient of determination $\left(R^{2}\right), R_{a d j}^{2}, R_{\text {pred }}^{2}$, coefficient of variation $(C . V$.$) , lack-of-fit and mean relative percent-$ age deviation (MRPD). Besides that, the developed models were assessed on the basis of the corrected Akaike information criterion (AICc) [31].

R-Project software (open source, http://cran.us.r-project. org) was used for developing the models, testing their adequacy, performing the ANOVA and optimizing the process factors. Previously, the Shapiro-Wilks normality test proved the HSO yield data were normally distributed at the 0.05 level of significance (BBD: statistic $=0.884$ and $p=0.067$; FCCD: statistic $=0.963$ and $p=0.712$ ). Also, the constant variance, the normality plots of residuals and the Cook's distance plots for both datasets were tested. These tests proved the constant variance, the normal distribution of residuals and the absence of any outliers in the tested datasets (Figure S1, Suppl. material). 
Table 1 Experimental matrix of the BBD.

\begin{tabular}{cccccccccc}
\hline & \multicolumn{3}{c}{ Coded levels } & \multicolumn{3}{c}{ Actual levels } & \multicolumn{3}{c}{ HSO yield, $Y(\%)$} \\
\cline { 2 - 7 } & $X_{1}$ & $X_{2}$ & $X_{3}$ & $X_{1}$ & $X_{2}$ & $X_{3}$ & Actual $^{\mathrm{a}}$ & $\begin{array}{l}\text { Predicted: } \\
\text { quadratic model }\end{array}$ & $\begin{array}{l}\text { Relative } \\
\text { deviation }^{\mathrm{b}}(\%)\end{array}$ \\
\hline 1 & -1 & -1 & 0 & 20 & 3 & 10 & 25.44 & 25.13 & 1.2 \\
2 & 1 & -1 & 0 & 70 & 3 & 10 & 29.30 & 29.46 & -0.5 \\
3 & -1 & 1 & 0 & 20 & 10 & 10 & 29.82 & 29.66 & 0.5 \\
4 & 1 & 1 & 0 & 70 & 10 & 10 & 29.13 & 29.44 & -1.1 \\
5 & -1 & 0 & -1 & 20 & 6.5 & 5 & 26.35 & 26.67 & -1.2 \\
6 & 1 & 0 & -1 & 70 & 6.5 & 5 & 29.52 & 29.38 & 0.5 \\
7 & -1 & 0 & 1 & 20 & 6.5 & 15 & 28.85 & 28.99 & -0.5 \\
8 & 1 & 0 & 1 & 70 & 6.5 & 15 & 30.72 & 30.40 & 1.1 \\
9 & 0 & -1 & -1 & 45 & 3 & 5 & 25.92 & 25.90 & 0.1 \\
10 & 0 & 1 & -1 & 45 & 10 & 5 & 26.03 & 25.87 & 0.6 \\
11 & 0 & -1 & 1 & 45 & 3 & 15 & 25.12 & 25.28 & -0.7 \\
12 & 0 & 1 & 1 & 45 & 10 & 15 & 29.81 & 29.83 & -0.1 \\
13 & 0 & 0 & 0 & 45 & 6.5 & 10 & 26.74 & 27.80 & -3.9 \\
14 & 0 & 0 & 0 & 45 & 6.5 & 10 & 28.85 & 27.80 & 3.7 \\
\hline MRPD $=$ & & & & & & & & & \pm 1.1 \\
\hline
\end{tabular}

${ }^{\mathrm{a}}$ Taken from the series 1 [3]. ${ }^{\mathrm{b}}$ Relative deviation $(\%)=$ (Actual - Predicted) 100/Actual.

c $M R P D=\sum \mid \operatorname{Re}$ lative deviation $\mid / n$, where $n=14$.

Table 2 Experimental matrix of the FCCD.

\begin{tabular}{|c|c|c|c|c|c|c|c|c|c|c|c|}
\hline \multirow{3}{*}{ Run } & \multicolumn{3}{|c|}{ Coded levels } & \multicolumn{3}{|c|}{ Actual levels } & \multicolumn{5}{|c|}{ HSO yield, $Y(\%)$} \\
\hline & \multirow{2}{*}{$X_{1}$} & \multirow{2}{*}{$X_{2}$} & \multirow{2}{*}{$X_{3}$} & \multirow{2}{*}{$X_{1}$} & \multirow{2}{*}{$X_{2}$} & \multirow{2}{*}{$X_{3}$} & \multirow{2}{*}{ Actual $^{\mathrm{a}}$} & Predicted & Rel. dev. ${ }^{\mathrm{b}}(\%)$ & Predicted & Rel. dev. $(\%)$ \\
\hline & & & & & & & & \multicolumn{2}{|c|}{ Linear model } & \multicolumn{2}{|c|}{ Reduced linear model } \\
\hline 1 & -1 & -1 & -1 & 20 & 3 & 5 & 25.34 & 25.40 & -0.2 & 25.73 & -1.5 \\
\hline 2 & 1 & -1 & -1 & 70 & 3 & 5 & 27.78 & 27.79 & 0.0 & 28.12 & -1.2 \\
\hline 3 & -1 & 1 & -1 & 20 & 10 & 5 & 26.06 & 27.15 & -4.2 & 27.48 & -5.5 \\
\hline 4 & 1 & 1 & -1 & 70 & 10 & 5 & 29.21 & 29.54 & -1.1 & 29.87 & -2.3 \\
\hline 5 & -1 & -1 & 1 & 20 & 3 & 15 & 25.50 & 26.06 & -2.2 & 25.73 & -0.9 \\
\hline 6 & 1 & -1 & 1 & 70 & 3 & 15 & 27.96 & 28.45 & -1.8 & 28.12 & -0.6 \\
\hline 7 & -1 & 1 & 1 & 20 & 10 & 15 & 28.46 & 27.81 & 2.3 & 27.48 & 3.4 \\
\hline 8 & 1 & 1 & 1 & 70 & 10 & 15 & 29.36 & 30.21 & -2.9 & 29.87 & -1.8 \\
\hline 9 & -1 & 0 & 0 & 20 & 6.5 & 10 & 27.36 & 26.61 & 2.8 & 26.61 & 2.8 \\
\hline 10 & 1 & 0 & 0 & 70 & 6.5 & 10 & 30.37 & 29.00 & 4.5 & 29.00 & 4.5 \\
\hline 11 & 0 & -1 & 0 & 45 & 3 & 10 & 27.00 & 26.92 & 0.3 & 26.92 & 0.3 \\
\hline 12 & 0 & 1 & 0 & 45 & 10 & 10 & 29.26 & 28.68 & 2.0 & 28.68 & 2.0 \\
\hline 13 & 0 & 0 & -1 & 45 & 6.5 & 5 & 27.57 & 27.47 & 0.4 & 27.80 & -0.8 \\
\hline 14 & 0 & 0 & 1 & 45 & 6.5 & 15 & 28.00 & 28.13 & -0.5 & 27.80 & 0.7 \\
\hline 15 & 0 & 0 & 0 & 45 & 6.5 & 10 & 26.74 & 27.80 & -4.0 & 27.80 & -4.0 \\
\hline 16 & 0 & 0 & 0 & 45 & 6.5 & 10 & 28.85 & 27.80 & 3.6 & 27.80 & 3.6 \\
\hline$M R I$ & & & & & & & & & \pm 2.0 & & \pm 2.2 \\
\hline
\end{tabular}

${ }^{\mathrm{a}}$ Taken from the series 1 of Kostić et al. [3]. ${ }^{\mathrm{b}}$ Relative deviation $(\%)=$ (Actual - Predicted) 100/Actual.

c $M R P D=\sum \mid \operatorname{Re}$ lative deviation $\mid / n$, where $n=16$. 
Table 3 Results of sequential model sum of squares test

\begin{tabular}{|c|c|c|c|c|c|c|c|}
\hline DoE & Source $^{a}$ & Sum of squares & $\mathrm{df}$ & Mean square & $F$-value & $p$-value & Remark \\
\hline \multirow{7}{*}{ BBD } & Mean vs Total & 10953.61 & 1 & 10953.61 & & & \multirow{7}{*}{$\begin{array}{r}\text { Suggested } \\
\text { Aliased }\end{array}$} \\
\hline & Linear vs Mean & 24.15 & 3 & 8.05 & 3.37 & 0.063 & \\
\hline & 2FI vs Linear & 10.84 & 3 & 3.61 & 1.94 & 0.212 & \\
\hline & Quadratic vs $2 \mathrm{FI}$ & 10.30 & 3 & 3.43 & 4.95 & 0.078 & \\
\hline & Cubic vs Quadratic & 0.55 & 3 & 0.18 & 0.08 & 0.961 & \\
\hline & Residual & 2.23 & 1 & 2.23 & & & \\
\hline & Total & 11001.67 & 14 & 785.83 & & & \\
\hline \multirow{7}{*}{ FCCD } & Mean vs Total & 12366.55 & 1 & 12366.55 & & & \multirow{4}{*}{ Suggested } \\
\hline & Linear vs Mean & 23.10 & 3 & 7.70 & 11.49 & 0.001 & \\
\hline & 2FI vs Linear & 1.32 & 3 & 0.44 & 0.59 & 0.637 & \\
\hline & Quadratic vs 2FI & 2.59 & 3 & 0.86 & 1.25 & 0.371 & \\
\hline & Cubic vs Quadratic & 1.08 & 4 & 0.27 & 0.18 & 0.932 & \multirow[t]{2}{*}{ Aliased } \\
\hline & Residual & 3.05 & 2 & 1.53 & & & \\
\hline & Total & 12397.69 & 16 & 774.86 & & & \\
\hline
\end{tabular}

a 2 FI model includes linear and two-factor interaction (2FI) terms.

\section{Results and discussion}

\subsection{BBD and FCCD-based models}

\subsubsection{Adequacy of the models}

The results of the three tests of the models' adequacy are given in Tables 3-5. Since all three tests indicated the cubic models were aliased, they should be rejected from further consideration as being unsuitable for the application in modeling and optimization. Besides that, the reduced cubic BBD- and FCCD-based models were aliased and insignificant, respectively so they also were disregarded from further consideration. On the other hand, the quadratic BBD- and linear FCCD-based models were recommended as the best by all three tests. The suggested models had an insignificant lack-of-fit, which was advisable (BBD- and FCCD-based models: $p=0.961$ and $0.935>0.050$, respectively; Table 4$)$. The quadratic BBD- based model had a high $R^{2}(0.942)$ and the $R_{\text {pred }}^{2}$ and $R_{a d j}^{2}$-values of 0.813 and 0.633 , respectively that were close to each other as expected, i.e. the difference between them was smaller than the advisable value of 0.2 . Therefore, this model was selected for further modeling and optimization of the HSO extraction. The corresponding 2FI and linear models based on the BBD should be disregarded as they had negative $R_{p r e d}^{2}$-values, indicating the overall mean as a better predictor of HSO yield than these models. The reduced quadratic BBD- and quadratic FCCD-based models had the acceptable $R^{2}$-values but the differences between the $R_{\text {pred }}^{2}$ - and $R_{a d j}^{2}$-values were larger than the recommended value of 0.2 [32], which compromised these models. Since no outlier value was observed in the analyzed dataset, the observed problem was not related to the dataset but to the models. As suggested by the performed tests, the linear FCCD-based model was selected for modeling. This model had a modest $R^{2}$-value of 0.742 and the difference between the $R_{\text {pred }}^{2}$ - and $R_{a d j}^{2}$-values was smaller than 0.2 .
Table 4 Results of lack-of-fit test

\begin{tabular}{llccccc}
\hline \multirow{2}{*}{ DoE } & Source & $\begin{array}{c}\text { Sum of } \\
\text { squares }\end{array}$ & df & $\begin{array}{c}\text { Mean } \\
\text { square }\end{array}$ & $F$-value & $p$-value \\
\hline BBD & Linear & 21.7 & 9 & 2.41 & 1.08 & 0.638 \\
& 2FI & 10.8 & 6 & 1.81 & 0.81 & 0.690 \\
& Quadratic $^{\mathrm{b}}$ & 0.5 & 3 & 0.18 & 0.08 & 0.961 \\
& Cubic $^{\mathrm{c}}$ & 0.0 & 0 & & & \\
& Pure Error $^{*}$ & 2.2 & 1 & 2.23 & & \\
\hline FCCD & Linear & 5.82 & 11 & 0.53 & 0.24 & 0.935 \\
& 2FI & 4.50 & 8 & 0.56 & 0.25 & 0.918 \\
& Quadratic & 1.90 & 5 & 0.38 & 0.17 & 0.940 \\
& Cubic & 0.83 & 1 & 0.83 & 0.37 & 0.652 \\
& Pure Error & 2.23 & 1 & 2.23 & & \\
\hline
\end{tabular}

a 2 FI model includes linear and two-factor interaction (2FI) terms.

${ }^{\mathrm{b}}$ Suggested model. ${ }^{\mathrm{c}}$ Aliased model.

Table 5 Results of model summary statistics test

\begin{tabular}{llllllr}
\hline \multirow{2}{*}{ DoE } & Source & $\begin{array}{l}\text { Stand. } \\
\text { dev. }\end{array}$ & $R^{2}$ & $R_{\text {adj }}^{2}$ & $R_{\text {pred }}^{2}$ & PRESS \\
\hline BBD & Linear & 1.55 & 0.502 & 0.353 & -0.032 & 49.62 \\
& 2FI & 1.37 & 0.728 & 0.495 & -0.277 & 61.35 \\
& Quadratic $^{\mathrm{b}}$ & 0.83 & 0.942 & 0.813 & 0.633 & 17.63 \\
& Cubic $^{\mathrm{c}}$ & 1.49 & 0.954 & 0.398 & & + \\
\hline FCCD & Linear $^{\mathrm{b}}$ & 0.82 & 0.742 & 0.677 & 0.553 & 13.92 \\
& 2FI & 0.86 & 0.784 & 0.640 & 0.011 & 30.79 \\
& Quadratic $^{\mathrm{a}}$ & 0.83 & 0.867 & 0.668 & 0.172 & 25.77 \\
& Cubic $^{\mathrm{c}}$ & 1.24 & 0.902 & 0.265 & -50.73 & 1611.0 \\
\hline
\end{tabular}

a 2 FI model includes linear and two-factor interaction (2FI) terms.

${ }^{\mathrm{b}}$ Suggested model. ${ }^{\mathrm{c}}$ Aliased model. 


\subsubsection{ANOVA and multiple non-linear regression results}

The ANOVA results obtained from the quadratic BBD- and linear FCCD-based models are presented in Table 6 while the corresponding Pareto plots are shown in Figure S2 (Suppl. material). The regression models derived from the FFD dataset and the corresponding BBD and FCCD sub-datasets as functions of HSO yield on temperature, solvent-to-seed ratio and extraction time are shown in Table 7. For the BBD-based quadratic model, the ANOVA indicated that only all three individual process factors and the quadratic term of extraction temperature had a statistically significant influence on HSO yield in the employed experimental region at the $95 \%$ confidence level whereas the other terms had a minor importance. This agreed with the results of the ANOVA applied to the reduced cubic [3] and quadratic FFD-based models (Table S1, Suppl. material).

On the other hand, the ANOVA results of assessing the FCCDbased linear model pointed out temperature and solvent-to-seed ratio as only significant terms, which was in agreement with the ANOVA results for the linear FFD-based model (Table S2, Supplementary material). The $F_{\text {model }}$ and $p$-values implied that both models were significant. As already said, the $F$-values of the lack-of-fit with the corresponding $p$-value larger than 0.050 were insignificant, meaning that the two models fitted well. Besides the $R^{2}$-values, the goodness of fit of both models was proven by very low $M R P D$-values (BBD: $\pm 1.1 \%, 14$ data; and FCCD: $\pm 2.0 \%, 16$
The linear regression coefficients of the quadratic BBD- and linear FCCD-based models were positive, indicating a positive influence of temperature, solvent-to-seed ratio and extraction time on HSO yield, which was also observed for the quadratic FFD-based model (Table 7). With increasing the extraction temperature and solvent-to-seed ratio, the oil solubility and diffusion rate increased while viscosity of the suspension decreased, enabling the achievement of a higher HSO yield in a shorter time. Naturally, the HSO yield increased with the progress of the extraction process. According to the quadratic BBD-based model, the solvent-to-seed ratio $\left(X_{2}\right)$ had the most significant effect on HSO yield and the extraction temperature $\left(X_{1}\right)$ was more influential than the extraction time $\left(X_{3}\right)$. However, the linear FCCD-based model pointed out the extraction temperature as the most influential process factor.

\subsubsection{Verification of the quadratic BBD- and reduced linear FCCD-based models}

The quadratic BBD- and reduced linear FCCD-based models were validated on the basis of the corresponding sub-datasets taken from the original FFD data [3] that were not included in their development. As it can be seen in Tables S3 and S4 (Supplementary material), the quadratic BBD- and reduced linear FCCD-based models fitted greatly the experimental data from outside of the experimental region employed in their derivation as the $M R P D$-values were only $\pm 4.1 \%$ (based on 40

Table 6 ANOVA results for the quadratic BBD- and linear FCCD- based models with the standardized effects

\begin{tabular}{|c|c|c|c|c|c|c|c|}
\hline Model & Source & $\begin{array}{l}\text { Sum of } \\
\text { squares }\end{array}$ & $\mathrm{df}$ & $\begin{array}{l}\text { Mean } \\
\text { square }\end{array}$ & $F$-value & $p$-value & $\begin{array}{c}\text { Standardized } \\
\text { effects }\end{array}$ \\
\hline \multirow{14}{*}{$\begin{array}{l}\text { BBD, } \\
\text { quadratic }\end{array}$} & Model & 45.29 & 9 & 5.03 & 7.26 & 0.036 & \\
\hline & $\mathrm{X}_{1}$ & 8.43 & 1 & 8.43 & 12.16 & 0.025 & $-3,33$ \\
\hline & $\mathrm{X}_{2}$ & 10.15 & 1 & 10.15 & 14.65 & 0.019 & $-3,66$ \\
\hline & $\mathrm{X}_{3}$ & 5.58 & 1 & 5.58 & 8.05 & 0.047 & $-2,71$ \\
\hline & $X_{1} X_{2}$ & 5.18 & 1 & 5.18 & 7.47 & 0.052 & 3,70 \\
\hline & $X_{1} X_{3}$ & 0.42 & 1 & 0.42 & 0.61 & 0.479 & 1,06 \\
\hline & $\mathrm{X}_{2} \mathrm{X}_{3}$ & 5.24 & 1 & 5.24 & 7.57 & 0.051 & $-3,72$ \\
\hline & $\mathrm{X}_{1}^{2}$ & 6.13 & 1 & 6.13 & 8.84 & 0.041 & $-4,50$ \\
\hline & $\mathrm{X}_{2}^{2}$ & 1.83 & 1 & 1.83 & 2.64 & 0.179 & 2,46 \\
\hline & $\mathrm{X}_{3}^{2}$ & 0.33 & 1 & 0.33 & 0.47 & 0.531 & 1,04 \\
\hline & Residual & 2.77 & 4 & 0.69 & & & \\
\hline & Lack-of-fit & 0.55 & 3 & 0.18 & 0.08 & 0.961 & \\
\hline & Pure error & 2.23 & 1 & 2.23 & & & \\
\hline & Cor. total & 48.06 & 13 & & & & \\
\hline \multirow{8}{*}{$\begin{array}{l}\text { FCCD, } \\
\text { linear }\end{array}$} & Model & 23.10 & 3 & 7.70 & 11.49 & 0.001 & \\
\hline & $\mathrm{X}_{1}$ & 14.30 & 1 & 14.30 & 21.34 & 0.001 & $-6,33$ \\
\hline & $\mathrm{X}_{2}$ & 7.69 & 1 & 7.69 & 11.47 & 0.005 & $-2,83$ \\
\hline & $\mathrm{X}_{3}$ & 1.10 & 1 & 1.10 & 1.64 & 0.224 & $-1,07$ \\
\hline & Residual & 8.04 & 12 & 0.67 & & & \\
\hline & Lack-of-fit & 5.82 & 11 & 0.53 & 0.24 & 0.935 & \\
\hline & Pure error & 2.23 & 1 & 2.23 & & & \\
\hline & Cor. total & 31.14 & 15 & & & & \\
\hline
\end{tabular}


Table 7 Model equations based on BBD, FCCD and FFD datasets.

\begin{tabular}{|c|c|c|c|}
\hline DoE & Model & Levels & Regression equation $^{\mathrm{a}}$ \\
\hline \multirow[t]{2}{*}{$\mathrm{BBD}$} & \multirow[b]{2}{*}{ Quadratic } & Coded & $\begin{aligned} Y= & 27.795+1.026 \cdot X_{1}+1.126 \cdot X_{2}+0.835 \cdot X_{3}-1.138 \cdot X_{1} \cdot X_{2}-0.325 \cdot X_{1} \cdot X_{3}+1.145 \cdot X_{2} \cdot X_{3} \\
& +1.384 \cdot X_{1}^{2}-0.756 \cdot X_{2}^{2}-0.319 \cdot X_{3}^{2}\end{aligned}$ \\
\hline & & Actual & $\begin{aligned} Y= & 22.067-0.048 \cdot X_{1}+1.055 \cdot X_{2}+0.114 \cdot X_{3}-0.013 \cdot X_{1} \cdot X_{2}-0.03 \cdot X_{1} \cdot X_{3}+0.065 \cdot X_{2} \cdot X_{3} \\
& +0.002 \cdot X_{1}^{2}-0.062 \cdot X_{2}^{2}-0.013 \cdot X_{3}^{2}\end{aligned}$ \\
\hline \multirow[t]{4}{*}{ FCCD } & \multirow{2}{*}{ Linear } & Coded & $Y=27.801+1.196 X_{1}+0.877 X_{2}+0.332 X_{3}$ \\
\hline & & Actual & $Y=23.356+0.048 X_{1}+0.251 X_{2}+0.066 X_{3}$ \\
\hline & \multirow{2}{*}{$\begin{array}{l}\text { Reduced } \\
\text { linear }\end{array}$} & Coded & $Y=27.801+1.196 X_{1}+0.877 X_{2}$ \\
\hline & & Actual & $Y=24.020+0.048 X_{1}+0.251 X_{2}$ \\
\hline \multirow[t]{6}{*}{ FDD } & \multirow{2}{*}{$\begin{array}{l}\text { Reduced } \\
\text { cubic }\end{array}$} & Coded & $\begin{aligned} Y= & 28.556+1.225 \cdot X_{1}+0.776 \cdot X_{2}+0.390 \cdot X_{3}-0.441 \cdot X_{1} \cdot X_{2}-0.100 \cdot X_{1} \cdot X_{3}+0.338 \cdot X_{2} \cdot X_{3} \\
& +0.525 \cdot X_{1}^{2}-0.630 \cdot X_{2}^{2}-0.461 \cdot X_{3}^{2}-0.172 \cdot X_{1} X_{2} X_{3}\end{aligned}$ \\
\hline & & Actual $^{\mathrm{b}}$ & $\begin{aligned} Y= & 28.556+1.225 \cdot X_{1}+0.776 \cdot X_{2}+0.390 \cdot X_{3}-0.441 \cdot X_{1} X_{2}-0.100 \cdot X_{1} X_{3}+0.338 \cdot X_{2} X_{3} \\
& +0.525 \cdot X_{1}^{2}-0.630 \cdot X_{2}^{2}-0.461 \cdot X_{3}^{2}\end{aligned}$ \\
\hline & \multirow[b]{2}{*}{ Quadratic } & Coded & $\begin{aligned} Y= & 28.556+1.225 \cdot X_{1}+0.776 \cdot X_{2}+0.390 \cdot X_{3}-0.441 \cdot X_{1} X_{2}-0.100 \cdot X_{1} X_{3}+0.338 \cdot X_{2} X_{3} \\
& +0.525 \cdot X_{1}^{2}-0.630 \cdot X_{2}^{2}-0.461 \cdot X_{3}^{2}\end{aligned}$ \\
\hline & & Actual & $\begin{aligned} Y= & 21.236+0.014 \cdot X_{1}+0.924 \cdot X_{2}+0.358 \cdot X_{3}-0.005 \cdot X_{1} X_{2}-0.001 \cdot X_{1} X_{3}+0.019 \cdot X_{2} X_{3} \\
& +0.001 \cdot X_{1}^{2}-0.051 \cdot X_{2}^{2}-0.018 \cdot X_{3}^{2}\end{aligned}$ \\
\hline & \multirow{2}{*}{ Linear } & Coded & $Y=28.179+1.225 X_{1}+0.776 X_{2}+0.390 X_{3}$ \\
\hline & & Actual & $Y=23.753+0.049 X_{1}+0.222 X_{2}+0.078 X_{3}$ \\
\hline
\end{tabular}

${ }^{a} X_{1}$ - temperature, $X_{2}$ - solvent-to-seed ratio and $X_{3}$ - extraction time; and $Y$ - HSO yield. ${ }^{\mathrm{b}}$ Taken from [3].

data) and $\pm 3.6 \%$ (based on 38 data), respectively. The reduced cubic FFD-based model resulted in the $M R P D$-value of $\pm 2.3 \%$ (54 data). Therefore, the simpler regression models showed a great fitness in the whole experimental cubic space and could be recommended for modeling of oilseed extraction instead of the more extensive FFD.

\subsection{Optimization of process factors}

For the selection of the optimal operating conditions using the quadratic BBD- and reduced linear FCCD-based models, the criterion of optimization was to get the maximum HSO yield with the process factors constrained to the applied experimental region. According to the quadratic BBD-based model, the maximum HSO yield about $31 \mathrm{~g} / 100 \mathrm{~g}$ could be obtained at either 20 or $70^{\circ} \mathrm{C}$ in $15 \mathrm{~min}$ if the solvent-to-seed ratio was close to $10: 1 \mathrm{~mL} / \mathrm{g}$. Under these conditions, the best predicted HSO yields at 20 and $70{ }^{\circ} \mathrm{C}$ were about $31.0-31.5$ and $30.8 \mathrm{~g} / 100 \mathrm{~g}$, respectively while the experimental HSO yields were 30.4 and $30.8 \mathrm{~g} / 100 \mathrm{~g}$, respectively. In the case of the reduced linear FCCD-based model, the best HSO yield of $29.87 \mathrm{~g} / 100 \mathrm{~g}$ could be achieved at $70{ }^{\circ} \mathrm{C}$ and the solvent-to-seed ratio of $10: 1 \mathrm{~mL} / \mathrm{g}$ in the employed range of extraction time (5-15 $\mathrm{min}$ ). Under the same extraction conditions, the experimental HSO yields achieved in 5, 10 and 15 min were $29.38 \pm 0.33,29.06 \pm 0.15$ and $30.00 \pm 1.28 \mathrm{~g} / 100 \mathrm{~g}$, respectively or the average HSO yield of $29.48 \pm 0.41 \mathrm{~g} / 100 \mathrm{~g}$ in the entire extraction time period of 5-15 $\min$.

\subsection{Comparison of the BBD-, FCCD- and FFD-based models}

Performances of the BBD-, FCCD- and FFD-based models could be compared with respect to their complexity, validity and accuracy, recommended optimal reaction conditions as well as costs and the required laboratory labor. Several criteria for comparing the models' performances are given in Table 8. Obviously, all compared models were significant and had an insignificant lack-of-fit with the $95 \%$ confidence level. Among the compared regression models, the quadratic BBDbased model had the best values of $R^{2}, R_{\text {adj }}^{2}, R_{\text {pred }}^{2}$ and MRPD. Besides that, the FCCD-based models have smaller AICcvalues than the FFD- and BBD-based models. All developed models led to the same optimal extraction temperature of $70^{\circ} \mathrm{C}$ although the quadratic BBD-based model pointed out also the extraction temperature of $20^{\circ} \mathrm{C}$ as the optimal one.

The reduced cubic and quadratic FFD-based models defined a somewhat lower solvent-to-seed ratio and a slightly shorter 
Table 8 Comparison of the regression models developed on the basis of the BBD, FCCD and FFD.

\begin{tabular}{|c|c|c|c|c|c|c|c|}
\hline \multirow{2}{*}{$\frac{\text { DoE }}{\text { Model }}$} & & \multirow{2}{*}{$\frac{\text { BBD }}{\text { Quadratic }}$} & \multicolumn{3}{|c|}{ FCCD } & \multicolumn{2}{|c|}{ FFD } \\
\hline & & & Linear & Reduced linear & Reduced cubic ${ }^{c}$ & Quadratic & Linear \\
\hline \multirow{3}{*}{$\begin{array}{l}\text { Significant } \\
\text { terms }\end{array}$} & Linear & $X_{1}, X_{2}, X_{3}$ & $\begin{array}{r}X_{1}, X_{2} \\
X_{3}\end{array}$ & $X_{1}, X_{2}$ & $X_{1}, X_{2}, X_{3}$ & $X_{1}, X_{2}, X_{3}$ & $X_{1}, X_{2}, X_{3}$ \\
\hline & Interaction & $X_{1}-X_{2}$ & & & $X_{1}-X_{2}$ & $X_{1}-X_{2}$ & \\
\hline & Quadratic & $X_{1}^{2}$ & & & $X_{1}^{2}$ & $X_{1}^{2}$ & \\
\hline \multirow[t]{13}{*}{ Criterion } & Number of runs & 14 & 16 & 16 & 54 & 54 & 54 \\
\hline & Number of coefficients & 10 & 4 & 3 & 11 & 10 & 4 \\
\hline & Efficiency $^{\mathrm{a}}$ & 0.714 & 0.250 & 0.188 & 0.204 & 0.185 & 0.074 \\
\hline & $\mathrm{AIC}^{\mathrm{b}}$ & 39.05 & 44.40 & 44.46 & 154.41 & 153.13 & 163.36 \\
\hline & $\mathrm{AICc}^{\mathrm{b}}$ & 171.05 & 50.40 & 48.09 & 162.02 & 159.41 & 164.61 \\
\hline & $F_{\text {model }}$-value & 7.26 & 11.49 & 15.63 & 12.15 & 13.56 & 25.00 \\
\hline & $p_{\text {model }}-$ value & 0.036 & $<0.001$ & $<0.001$ & $<0.0001$ & $<0.0001$ & $<0.0001$ \\
\hline & $R^{2}$ & 0.942 & 0.742 & 0.706 & 0.739 & 0.735 & 0.600 \\
\hline & $R_{a d j}^{2}$ & 0.813 & 0.677 & 0.661 & 0.678 & 0.681 & 0.576 \\
\hline & $R_{\text {pred }}^{2}$ & $0.633^{\mathrm{c}}$ & 0.553 & 0.549 & 0.604 & 0.610 & 0.536 \\
\hline & $p_{\text {lack-of-fit }}$ & 0.960 & 0.935 & 0.927 & 0.692 & 0.712 & 0.175 \\
\hline & C.V., $\%$ & 3.0 & 2.9 & 3.0 & 3.2 & 3.2 & 3.7 \\
\hline & $M R P D, \%$ & \pm 1.1 & \pm 2.0 & \pm 2.2 & \pm 2.3 & \pm 2.3 & \pm 2.9 \\
\hline \multirow{3}{*}{$\begin{array}{l}\text { Optimal } \\
\text { process } \\
\text { conditions }\end{array}$} & $X_{1},{ }^{\circ} \mathrm{C}$ & 20 or 70 & 70 & 70 & 70 & 70 & 70 \\
\hline & $X_{2}, \mathrm{~mL} / \mathrm{g}$ & $10: 1$ & $10: 1$ & $10: 1$ & $7.6: 1$ & $7.9: 1$ & $10: 1$ \\
\hline & $X_{3}, \min$ & 15 & 15 & 13.6 & 11.9 & 12.3 & 15 \\
\hline \multirow{2}{*}{ HSO yield } & Predicted, g/100 g & 30.1 & 30.2 & 29.9 & 30.4 & 30.4 & 30.6 \\
\hline & Actual, g/100 g & 30.5 & 30.0 & - & - & - & 30.0 \\
\hline
\end{tabular}

${ }^{a}$ Defined as the number of coefficients in the model equation divided by the number of experiments. ${ }^{\mathrm{b}}$ AIC - Akaike information criterion and AICc - corrected Akaike information criterion [31]. ${ }^{\mathrm{c}}$ Taken from [3].

extraction time than the BBD and FCCD-based models. The best HSO yields predicted by all analyzed models were close the experimental yields obtained under the same optimum extraction conditions (about $30 \mathrm{~g} / 100 \mathrm{~g}$ ). It should be emphasized that the BBD and FCCD-based models involve a much smaller number of experimental runs, so they generate lower costs, require less labor and consume shorter time than the FFD-based models. In line with all above-mentioned arguments, the BBD and FCCD could be suggested for collecting the data intended for the optimization of liquid-solid extraction processes instead of the more extensive FDD.

\section{Conclusion}

$\mathrm{BBD}, \mathrm{FCCD}$ and FFD were compared as statistical multivariate methods for the collection of experimental data needed for the modeling and optimization of HSO extraction by $n$-hexane by the RSM. When combined with the RSM, all three methods were efficient in the statistical modeling and optimization of the influential process variables and led to almost the same optimal process conditions and the predicted HSO yield. Having better statistical performances and being economically advantageous over the FFD with repetition, the BBD and FCCD combined with the RSM are recommended for the optimization of solid-liquid extraction processes. These simpler experimental designs can successfully be applied in the whole experimental cubic space employed in the derivation of the models.

\section{Acknowledgement}

This work has been funded by the Ministry of Education, Science and Technological Development of the Republic of Serbia, Serbia (Project III 45001).

\section{References}

[1] Milenović, D., Veljković, V. B., Todorović, B., Stanković, M. "Extraction of resinoids from from St. John's wort (Hypericum perforatum L.). I. Efficiency and optimization of extraction." Hemijska industrija. 56, pp. 54-59. 2002.

https://doi.org/10.2298/HEMIND0202060V

[2] Rajković, K. M., Jeremić, S., Milić, P. S., Kostić, M., Arsić-Arsenijević, V., Gavrilović, M., Krstić, B. "Optimization of ultrasound-assisted extraction of total extractive substances from Galium verum L." Periodica Polytechnica Chemical Engineering. 61(3), pp. 200-205. 2017. https://doi.org/10.3311/PPch.9580 
[3] Kostić, M. D., Joković, N. M., Stamenković, O. S., Rajković, K. M., Milić, P. S., Veljković, V.B. "Optimization of hempseed oil extraction by n-hexane." Industrial Crops and Products. 48, pp. 133-143. 2013. https://doi.org/10.1016/j.indcrop.2013.04.028

[4] Silva, E. M., Rogez, H., Larondelle, Y. "Optimization of extraction of phenolics from Inga edulis leaves using response surface methodology." Separation and Purification Technology. 55, pp. 381-387. 2007. https://doi.org/10.1016/j.seppur.2007.01.008

[5] Gong, Y., Hou, Z., Gao, Y., Xue, Y., Liu, X., Liu, G. "Optimization of extraction parameters of bioactive components from defatted marigold (Tagetes erecta L.) residue using response surface methodology." Food and Bioproducts Processing. 90, pp. 9-16. 2012.

https://doi.org/10.1016/j.fbp.2010.12.004

[6] Kim, H.-K., Do, J.-R., Lim, T.-S., Akram, K., Yoon, S.-R., Kwon, J.-H. "Optimization of microwave-assisted extraction for functional properties of Vitis coignetiae extract by response surface methodology." Journal of the Science of Food and Agriculture. 92, pp. 1780-1785. 2012. https://doi.org/10.1002/jsfa.5546

[7] Li, H., Deng, Z., Wu, T., Liu, R., Loewen, S., Tsao, R. "Microwave-assisted extraction of phenolics with maximal antioxidant activities in tomatoes." Food Chemistry. 130, pp. 928-936. 2012. https://doi.org/10.1016/j.foodchem.2011.08.019

[8] Tabaraki, R., Heidarizadi, E., Benvidi, A. "Optimization of ultrasonic-assisted extraction of pomegranate (Punica granatum L.) peel antioxidants by response surface methodology." Separation and Purification Technology. 98, pp. 16-23. 2012.

https://doi.org/10.1016/j.seppur.2012.06.038

[9] Wang, H., Liu, Y., Wei, S., Yan, Z. "Application of response surface methodology to optimize supercritical carbon dioxide extraction of essential oil from Cyperus rotundus Linn." Food Chemistry. 132, pp. 582587. 2012.

https://doi.org/10.1016/j.foodchem.2011.10.075

[10] Ganesapillai, M., Mathew, M., Singh, A., Simha, P. "Influence of microwave and ultrasound pretreatment on solvent extraction of bio-components from walnut (Julgans regia L.) shells." Periodica Polytechnica Chemical Engineering. 60(1), pp. 40-48. 2016.

https://doi.org/10.3311/PPch.8480

[11] Zahedi, G., Azarpour, A. "Optimization of super-critical carbon dioxide extraction of Passiflora seed oil." Journal of Supercritical Fluids. 58, pp. 40-48. 2011.

https://doi.org/10.1016/j.supflu.2011.04.013

[12] Li, T., Qu, X.-Y., Zhang, Q.-A., Wang, Z.-Z. "Ultrasound-assisted extraction and profile characteristics of seed oil from Isatis indigotica Fort." Industrial Crops and Products. 35, pp. 98-104. 2012. https://doi.org/10.1016/j.indcrop.2011.06.013

[13] Pouralinazar, F., Yunus, M. A. C., Zahedi, G. "Pressurized liquid extraction of Orthosiphon stamineus oil: experimental and modeling studies." Journal of Supercritical Fluids. 62, pp. 88-95. 2012. https://doi.org/10.1016/j.supflu.2011.12.009

[14] Li, H.-Z., Zhang Z.-J., Hou T.-Y. Li, X.-J., Chen T. "Optimization of ultrasound-assisted hexane extraction of perilla oil using response surface methodology." Industrial Crops and Products. 76 pp. 18-24. 2015. https://doi.org/10.1016/j.indcrop.2015.06.021

[15] Banik, R. M., Pandey, D. K. "Optimizing conditions for oleanolic acid extraction from Lantana camara roots using response surface methodology." Industrial Crops and Products. 27, pp. 241-248. 2008. https://doi.org/10.1016/j.indcrop.2007.09.004

[16] Pan, G., Yu, G., Zhu, C., Qiao, J. "Optimization of ultrasound-assisted extraction (UAE) of flavonoids compounds (FC) from hawthorn seed (HS)." Ultrasonic Sonochemistry. 19, pp. 486-490. 2012. https://doi.org/10.1016/j.ultsonch.2011.11.006
[17] Wu, Y., Wang, X., Fan, E. "Optimisation of ultrasound-assisted extraction of puerarin and total isoflavones from Puerariae Lobatae Radix (Pueraria lobata (Wild.) Ohwi) with response surface methodology." Phytochemical Analysis. 23, pp. 513-519. 2012.

https://doi.org/10.1002/pca.2349

[18] Sheng, Z.-L., Wan, P.-F., Dong, C.-L., Li, Y.-H. "Optimization of total flavonoids content extracted from Flos populi using response surface methodology." Industrial Crops and Products. 43, pp. 778-786. 2013. https://doi.org/10.1016/j.indcrop.2012.08.020

[19] Kolodziejczyk, P., Ozimek, L., Kozłowska, J. "The application of flax and hemp seeds in food, animal feed and cosmetics production." In: Kozłowski, R. M. (ed.) Handbook of Natural Fibres Processing and Applications, Woodhead Publishing Series in Textiles. Vol 2., (pp. 329-366). Woodhead Publishing. 2012.

https://doi.org/10.1533/9780857095510.2.329

[20] Rehman, M. S. U., Rashid, N., Saif, A., Mahmood, T., Han, J.-I. "Potential of bioenergy production from industrial hemp (Cannabis sativa): Pakistan perspective." Renewable and Sustainable Energy Reviews. 18, pp. 154-164. 2013.

https://doi.org/10.1016/j.rser.2012.10.019

[21] Dunford, N. T. "Hemp and flaxseed oil: properties and applications for use in food." In: Talbot, G. (ed.) Specialty Oils and Fats in Food and Nutrition - Properties, Processing and Applications, Woodhead Publishing Series in Food Science, Technology and Nutrition. (pp. 39-63). Woodhead Publishing. 2015.

https://doi.org/10.1016/B978-1-78242-376-8.00002-8

[22] Li, S.-Y., Stuart, J. D., Parnas, R. S. "The feasibility of converting Cannabis sativa L. oil into biodiesel." Bioresource Technology. 101, pp. 8457-8460. 2010. https://doi.org/10.1016/j.biortech.2010.05.064

[23] Kostić, M. D., Joković, N. M., Stamenković, O. S., Rajković, K. M., Milić, P. S., Veljković, V. B. "The kinetics and thermodynamics of hempseed oil extraction by $n$-hexane." Industrial Crops and Products. 52, pp. 679- 686. 2014.

https://doi.org/10.1016/j.indcrop.2013.11.045

[24] Deferne, J. L., Pate, D. W. "Hemp seed oil: a source of valuable essential fatty acids." Journal of the International Hemp Association. 3, pp. 4-7. 1996.

[25] Anwar, F., Latif, S., Ashraf, M. "Analytical characterization of hemp (Cannabis sativa) seed oil from different agro-ecological zones of Pakistan." Journal of the American Oil Chemists' Society. 83, pp. 323-329. 2006. https://doi.org/10.1007/s11746-006-1207-x

[26] Aladić, K., Jokić, S., Moslavac, T., Tomas, S., Vidović, S., Vladić, J., Šubarić, D. "Cold pressing and supercritical $\mathrm{CO}_{2}$ extraction of hemp (Cannabis sativa) seed oil." Chemical and Biochemical Engineering. 28, pp. 481-490. 2014.

https://doi.org/10.15255/CABEQ.2013.1895

[27] Kriese, U., Schumann, E., Weber, E.W., Beyer, M., Bruhl, L., Matthaus, B. "Oil content, tocopherol composition and fatty acid patterns of the seeds of 51 Cannabis sativa L. genotypes." Euphytica. 137, pp. 339-351. 2004. https://doi.org/10.1023/B:EUPH.0000040473.23941.76

[28] Da Porto, C., Voinovich, D., Decorti, D., Natolino, A. "Response surface optimization of hemp seed (Cannabis sativa L.) oil yield and oxidation stability by supercritical carbon dioxide extraction." Journal of Supercritical Fluids. 68, pp. 45-51. 2012. https://oi.org/10.1016/j.supflu.2012.04.008

[29] Aladić, K., Jarni, K., Barbir, T., Vidović, S., Vladić, J., Bilić, M., Jokić S. "Supercritical $\mathrm{CO}_{2}$ extraction of hemp (Cannabis sativa L.) seed oil." Industrial Crops and Products. 76, pp. 472-478. 2015. https://doi.org/10.1016/j.indcrop.2015.07.016 
[30] Aladić, K., Vidović, S., Vladić, J., Balić, D., Jukić, H., Jokić, S. "Effect of supercritical $\mathrm{CO}_{2}$ extraction process parameters on oil yield and pigment content from by-product hemp cake." International Journal of Food Science and Technology. 51, pp. 885-893. 2016. https://doi.org/10.1111/ijfs.13041

[31] Burnham, K., Anderson, D., Huyvaert, K. P. "AIC model selection and multimodel inference in behavioral ecology: some background, observations, and comparisons." Behavioral Ecology and Sociobiology. 65, pp. 23-35. 2011 https://doi.org/10.1007/s00265-010-1084-z

[32] Anderson, M. J. "Statistics Made Easy_Blog". 10(6), 2010. [Online]. Available from: http://www.statease.com/news/faqalert10-06.html [Accessed: 15th February 2014]. 